\title{
Comparison of a new immunoassay and PCR-based method for quantification of microRNAs in whole blood. A pilot methodical study
}

\author{
David Stejskal $^{\mathrm{a}, \mathrm{b}, \mathrm{d}}$, Martina Hlozankovac, Radka Sigutova ${ }^{\mathrm{a}, \mathrm{b}}$, Katerina Andelova ${ }^{\mathrm{a}, \mathrm{b}}$, Zdenek Svagera ${ }^{\mathrm{a}, \mathrm{b}}$, Marek Svestak ${ }^{\mathrm{d}}$
}

Background. MicroRNAs (miRNAs) are new generation biomarkers used in oncology, cardiology, metabolic syndrome, obesity or in neurology. miRNAs are short non-coding RNA molecules that regulate gene expression in eukaryotes. Aim. To compare a new commercial method for establishing miRNA (imunoassay) with a commercial kit RT qPCR. Methods. RNA was isolated from whole blood samples obtained from four healthy volunteers. The isolates were liquated and miRNA-93-5p and miRNA-23a-3p were measured independently with commercial hsa-miR-93-5p miREIA and hsa-miR-23a-3p miREIA, and commercial RT-qPCR kits.

Results. Both miRNAs had good analytical characteristics, very good correlation with RT qPCR. The results between immunoassay and RT qPCR did not statistically differ. A method based on ELISA was faster ( $2 \mathrm{~h}$ with ELISA vs. $3 \mathrm{~h}$ with qPCR) and had lower CV then a method based on RT qPCR (see more text).

Conclusion. MicroRNAs from blood or derived fractions are particularly interesting candidates for routine laboratory applications. The immunoassay can be performed on any device that processes the ELISA plates and is therefore available in almost every laboratory.

Key words: microRNA, PCR, immunoassay, ELISA

Received: June 4, 2018; Accepted: December 12, 2018; Available online: December 17, 2018

https://doi.org/10.5507/bp.2018.080

anstitute of Laboratory Diagnostics, University Hospital Ostrava, Czech Republic

${ }^{b}$ Faculty of Medicine, University of Ostrava, Czech Republic

'Biovendor R\&D, Brno-Karasek, Czech Republic

'Stredomoravska Nemocnicni, Member of AGEL, Czech Republic

Corresponding author:David Stejskal, e-mail:david.stejskal@fno.cz

\section{INTRODUCTION}

MicroRNAs (miRNAs) are small (21-24 nucleotides) non-coding RNAs, which are involved in negative posttranscriptional regulation of gene expression. One miRNA molecule can have up to hundreds of target mRNAs and one mRNA can be regulated by multiple miRNAs, creating a complex regulatory network in the body/organism ${ }^{1}$.

Changes in intracellular miRNA levels affect gene expression, alter cell signalling, and significantly affect cellular metabolism. They regulate physiological processes including cell differentiation, regeneration and apoptosis, as well as pathological processes such as neoplastic transformation of cells. Therefore, it is not surprising that aberrant miRNA expression is involved in the pathogenesis of many diseases including cardiovascular diseases, neurodegenerative diseases, hematologic diseases, osteologic diseases and cancer. To this day, more than 2,650 different microRNAs have been described in various documents ${ }^{2-12}$.

In addition to the intracellular occurrence, microRNAs were also detected in the extracellular area - in the blood and its derivatives (plasma, serum), but also in the urine, saliva and other body fluids ${ }^{5,6}$. It has been proven that levels of circulating microRNAs are not random and reflect the events occurring within the organism/body.
The gathered data, together with the proven high miRNA stability, place the circulating miRNA into the role of a potentially useful, clinically relevant biomarkers. Finding specific miRNAs or groups (profiles) of several miRNAs at once, in order toserve as diagnostic or prognostic sets, is now one of the main targets of research in this $\operatorname{area}^{2-5,7}$.

Amount of known miRNAs is summarised in mirBase database (www.mirbase.org) (ref. ${ }^{6}$ ). Detection and quantification of small non-coding RNAs is a challenging and interesting topic of contemporary science. Not only a small length of these molecules (about 25 nucleotides) and their low concentration in body fluids, but also the existence of sequence differences in unit bases in some types of short RNA (isomiRs), are key points for using these molecules as markers in routine diagnostics. The most common techniques for detecting small RNAs can be divided into many groups, and their combinations: Polymerase Chain Reaction (PCR), Microarrays, New Generation Sequencing (NGS), etc. (ref. ${ }^{12-16}$ ). Recently, the new immunoassay for detection miRNAs was described ${ }^{15}$. Also nanomachine-based strategy possesses significant potential to be an innovation in miRNA analysis methodology ${ }^{17,18}$. 


\section{METHODS}

Main objectives of the project is optimization of existing method and the use the commercional kit for quantitation of miRNA based on ELISA format, where the monoclonal antibody pre-coated to microplate wells catches perfectly matched DNA/miRNA hybrids and immobilize them. The solid phase formed by monoclonal antibody and DNA/miRNA hybrids is incubated with streptavidin-HRP conjugate. For visualization of resulting complexes is used chromogenic substrate. The absorbance is proportional to the concentration of specific miRNA. ELISA assay can be run on common immunoassay equipment, is compatible with standard clinical workflow, does not require amplification steps and results are obtained in less than three hours including miRNA profiling.

RNA was isolated from whole blood samples obtained from four healthy volunteers. The isolates were liquated and miRNA-93-5p and miRNA-23a-3p were measured independently with commercial hsa-miR-93-5p miREIA and hsa-miR-23a-3p miREIA, and commercial qRT-PCR kits. These methods were chosen because the immunoassays were first prepared for validation.

\section{The procedure of miRNA's isolation:}

Whole blood samples from 4 healthy volunteers were collected in PAXgene Blood RNA Tubes (Preanalytix) and handled according to manufacturer's instructions. Total RNA including miRNA was purified manually with commercial RNA isolation kit. Briefly, tubes were thawed for $2 \mathrm{~h}$ at a room temperature and then centrifuged for $10 \mathrm{~min}$ at $4,500 \mathrm{~g}$. The supernatant was removed immediately, the pellets were resuspended in $4 \mathrm{~mL}$ RNase-free water and newly centrifugated. $500 \mathrm{uL}$ of QIAzol solution (Qiagen) was added to obtained pellets. Then the isolation proceeded according to the manufacturer's recommendations. The total elution volume was $50 \mathrm{uL}$ of RNAse-free $\mathrm{H}_{2} \mathrm{O}$. Isolated RNA was stored at $-80^{\circ} \mathrm{C}$ until.

\section{Expression of miRNAs}

The expression of miRNAs was determined by a commercial RT-qPCR system with the use of specific commercial Assays and commercial Master Mix II, with UNG. The reactions in triplicates were run on thermocycler mic (BMS) under the following thermal cycling condition: 2 min at $50{ }^{\circ} \mathrm{C} ; 10 \mathrm{~min}$ at $95^{\circ} \mathrm{C}$ and 45 cycles of $15 \mathrm{~s}$ at $95{ }^{\circ} \mathrm{C}$ and $1 \mathrm{~min}$ at $60{ }^{\circ} \mathrm{C}$. The Data were mathematically normalized to interval $0-1$ for correlation purposis. Measurements were repeated five times in five days and reproducibility of the two methods were compared.

\section{Measurement of miRNAs with ELISA}

The absolute quantification of miRNAs was determined by miREIA assays according to manufacturer's instructions. Briefly, after RNA isolation, samples were hybridized to complementary biotinylated probe to perform perfectly matched DNA/miRNA hybrids. The hybridization was performed on thermocycler PeqStar (Peqlab) under following thermal cycling condition: $3 \mathrm{~min}$ at $85^{\circ} \mathrm{C}, 2$ min at $4{ }^{\circ} \mathrm{C}$ and $5 \mathrm{~min}$ at $37^{\circ} \mathrm{C}$. Hybridization was followed by washing steps, streptavidin-HRP was added and microtiter plate was incubated for $30 \mathrm{~min}$ at $37^{\circ} \mathrm{C}$. Then, TMB substrate was added and incubated $15 \mathrm{~min}$ at laboratory temperature. Finally, stop solution was added and absorbance at $450 \mathrm{~nm}$ was measured by absorbance reader (BioTek). Concentrations of miRNAs were calculated from calibration curve using GEN software. The Data were mathematically normalized to interval $0-1$ for correlation purposes. Measurements were repeated five times in five days and reproducibility of the two methods were compared. In the PCR, minimal negative controls for reverse transcription and PCR were used. In other comparative tests, normalization was used for exogenous Cel-miR-39 control.

Both methods (miREIA and qRT-PCR) use synthetic miRNA for generating standard curve. In miREIA, the standard curve is constructed by plotting absorbance values against concentrations of miRNA standards. In qRT-PCR method, the standard curve is constructed by plotting $\mathrm{Ct}$ values against concentrations of miRNA standards. Concentrations of samples are determined using these standard curves. Due to different principle of miREIA and qRT-PCR methods, observed sample concentrations are unified in range from 0 to 1 taking into consideration their measured levels.

\section{Statistical data procecessing}

The Medcalc program (Ostend, Belgium) was used to statistically process the results. The basic parameters will be evaluated, including normality tests, exploitation analysis and remote values detection. There was done comparison measured results four probands with non-parametric methods for small number of probands. Spearman rank correlation (after mathematicaly normalisation) was used. Mann Whitney non-parametrical test and $\mathrm{F}$ test variations (based on a small number of probands and differencies between average and median we have chosen non-parametrical tests) were used.

\section{RESULTS}

Both analysis of miRNA's had good analytical characteristics. mRNA was quantified od the basis ELISA format (more above ). This method is also known as miREIA (miREIA for short). Because only 4 probands were examined, this study has to be considered as pilot study. There are listed common analytical characteristics of two used miRNAs (miRNA-93-5p and miRNA-23a-3p) in the below tables. It is apparent that CVs of immunoassays are better than in RT qPCR. Immunoassays for both miRNAs had good analytical characteristic and results indicated good cortrelation with qPCR results. (Fig. 1, 2, Table 1-9).

Coefficient of variation $(\mathrm{CV})$ was calculated from average values of absolute concentrations obtained from miREIA or relative concentrations obtained from qRTPCR measurements. miREIA showed better Run-to-Run reproducibility than qRT-PCR method. 


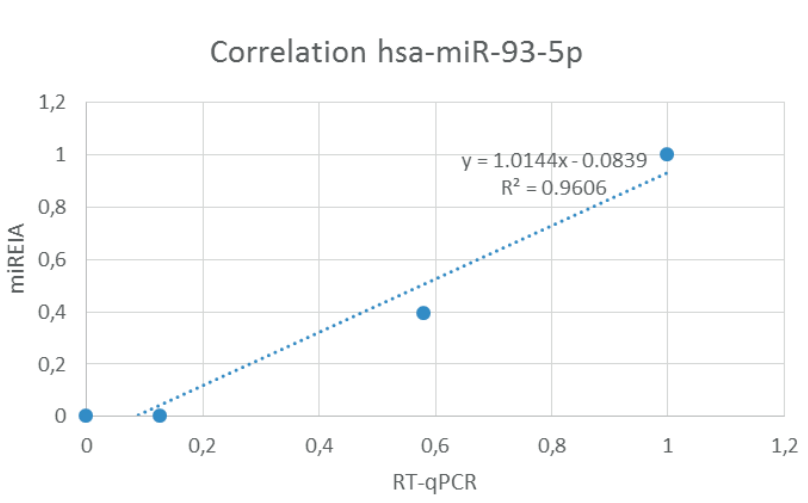

Fig. 1. Correlations between HSA-miR-93-5p immunomethod vs. qRT PCR (normalized concentrations). (Fig. $1-\mathrm{R}^{2}=0.96$ )

Because the results of miRNAs obtain from immunoassay cannot be easily compared with results of miRNAs obtain by PCR, we had to do mathematicaly simple normalisation of data in the interval 0-1. After that, we could establish correlation graph.

We have performed Mann Whitney non-parametrical test and $\mathrm{F}$ test variations (based on a small number of probands and differencies between average and median we have chosen non-parametrical tests).

In both cases the values measured immunoassay and PCR did not differ $(P=0.99 ; P=0.98)$ for HSA-MIR-23.3p; similarly for HSA-MIR-93-5p $(P=0.88 ; P=0.89)$

\section{DISCUSSION}

MicroRNA can be measured with various technologies. Probably the most common are methods based on RT PCR, microchips and NGS. We have tested completely new applications of imunomethods basis ELISA. Each of these detection technologies (qPCR, microarrayes, NGS) has its advantages and disadvantages for the use in the clinical laboratory.

\section{Detection technology based on PCR}

Since the discovery of reverse transcription PCR (RT PCR), PCR-based systems are the most widely used methods for detecting RNA sequences. In this technology, the RNA molecule is first enzymatically transcribed (via the reverse transcriptase enzyme and the RT primer) into the cDNA sequence, which is then amplified by DNA polymerase using two specific primers. The PCR reaction can be visualized in real time (qRT PCR) using a sequence non-specific (Sybergreen) or sequence-specific (TaqMan system) fluorescent labels/ markers. Unfortunately, in the context of a short RNA detection, this standard qRT PCR system is not well suited because the RT primers do not have enough space to bind the target RNA due to their short length. Therefore, new approaches to the detection of short RNA molecules have to be applied, such as using a special RT primer, amplification of circular molecules (RCA), poly-tailing reaction or ligation reaction. So far, several methods of quantifi-

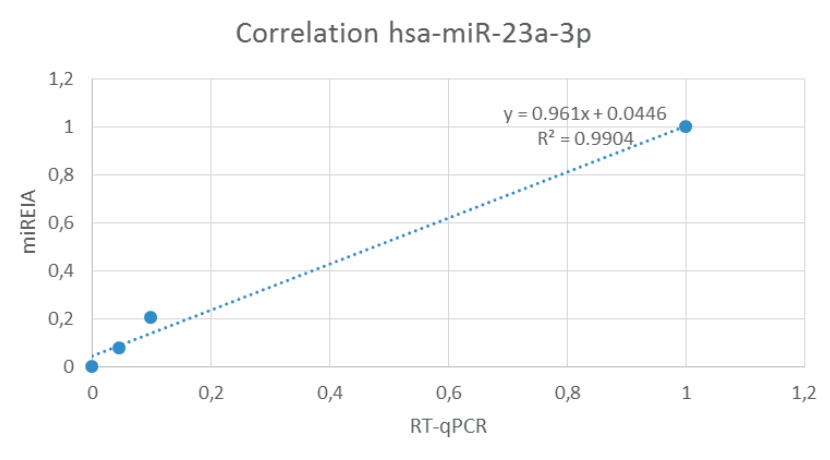

Fig. 2. Correlations between HSA-miR-23a-3p immunoassay vs. RT qPCR (normalized concentrations). (Fig. $2-\mathrm{R}^{2}=0.99$ )

Table 1. Run-to-run variability.

\begin{tabular}{lccc}
\hline miRNA & Sample ID & $\begin{array}{c}\text { miREIA } \\
\text { CV (\%) }\end{array}$ & $\begin{array}{c}\text { qPCR } \\
\text { CV dCT (\%) }\end{array}$ \\
\hline miR-93-5p & 1 & 4 & 58 \\
& 2 & 13 & 59 \\
miR-23a-3p & 3 & 12 & 49 \\
& 4 & 12 & 81 \\
& 1 & 8 & 25 \\
& 2 & 17 & 19 \\
& 3 & 6 & 22 \\
& 4 & 5 & 17 \\
\hline
\end{tabular}

cation of miRNA based on qRT PCR have been developed, and many of them are also commercially available.

Many microRNAs (miRNAs) are reported as disease markers for various human pathologies 18-21, but only a small fraction is translated to routine clinical use. Interlaboratory variability and the consequent potential misinterpretation of results seem to be the biggest constraints of miRNA biomarker functionality. Absolute quantification ensured by exact calibration may solve this problem and help to translate miRNA biomarkers to diagnostic use. To address this problem, we have used a novel method for quantification of miRNA based on immunoassay, the miREIA - microRNA Enzyme Immunoassay kit. Recently there was described completely new and simple method for quantifications of miRNAs based on immunochemical principle. In comparison with other other older methods it is a fast simple low cost and analytical stable 19-23.

Immunoassay platforms are already routinely used in clinical laboratories worldwide, and many immunological tests are carried out on these commercial systems. Immunoassays are also adaptable to immunoassay analysers. The general principle of immunoassay technique is detection or quantification of analyte (microRNA) in the sample comprising an immune reaction between an antibody and an analyte. The first miRNA measurement principle on the basis of an immunoassay format was developed by Kappel and al. ${ }^{24}$. The study was published in 2015 in Clinical Chemistry Journal. The 
Table 2. Intra-assay (Within-Run) ( $\mathrm{n}=8)$.

\begin{tabular}{cccc}
\hline Specimen & $\begin{array}{c}\text { Mean } \\
(\mathrm{amol} / \mu \mathrm{L})\end{array}$ & $\begin{array}{c}\mathrm{SD} \\
(\mathrm{amol} / \mu \mathrm{L})\end{array}$ & $\begin{array}{c}\mathrm{CV} \\
(\%)\end{array}$ \\
\hline 1 & 3.44 & 0.31 & 9.1 \\
2 & 0.96 & 0.06 & 7.4 \\
3 & 0.39 & 0.03 & 8.6 \\
\hline
\end{tabular}

hsa-miR-93-5p miREIA

Sensitivity: $0.13 \mathrm{amol} / \mu \mathrm{L}$

Table 3. Inter-assay (Run-to Run) ( $n=5)$.

\begin{tabular}{cccc}
\hline Specimen & $\begin{array}{c}\text { Mean } \\
(\mathrm{amol} / \mu \mathrm{L})\end{array}$ & $\begin{array}{c}\mathrm{SD} \\
(\mathrm{amol} / \mu \mathrm{L})\end{array}$ & $\begin{array}{c}\mathrm{CV} \\
(\%)\end{array}$ \\
\hline 1 & 848.3 & 34.3 & 4.0 \\
2 & 361.2 & 43.5 & 12.0 \\
3 & 43.7 & 5.2 & 12.0 \\
\hline
\end{tabular}

hsa-miR-93-5p miREIA

Sensitivity: $0.13 \mathrm{amol} / \mu \mathrm{L}$

Table 4. Spiking recovery.

\begin{tabular}{cccc}
\hline Specimen & $\begin{array}{c}\text { Observed } \\
(\mathrm{amol} / \mu \mathrm{L})\end{array}$ & $\begin{array}{c}\text { Expected } \\
(\mathrm{amol} / \mu \mathrm{L})\end{array}$ & $\begin{array}{c}\text { Recovery } \\
\text { O/E }(\%)\end{array}$ \\
\hline \multirow{3}{*}{1} & 50.08 & - & - \\
& 107.40 & 113.69 & 94.5 \\
& 73.55 & 80.95 & 90.9 \\
& 54.78 & 64.93 & 84.4 \\
\hline \multirow{2}{*}{2} & 7.22 & - & - \\
& 12.05 & 11.83 & 101.8 \\
& 9.75 & 9.57 & 101.9 \\
& 8.57 & 8.15 & 105.1 \\
\hline
\end{tabular}

hsa-miR-93-5p miREIA

Sensitivity: $0.13 \mathrm{amol} / \mu \mathrm{L}$

Table 5. Linearity.

\begin{tabular}{ccccc}
\hline Specimen Dilution & $\begin{array}{c}\text { Observed } \\
(\mathrm{amol} / \mu \mathrm{L})\end{array}$ & $\begin{array}{c}\text { Expected } \\
(\mathrm{amol} / \mu \mathrm{L})\end{array}$ & $\begin{array}{c}\text { Recovery } \\
\mathrm{O} / \mathrm{E}(\%)\end{array}$ \\
\hline \multirow{3}{*}{1} & - & 192.08 & - & - \\
& $2 \mathrm{x}$ & 103.8 & 96.04 & 108.1 \\
& $4 \mathrm{x}$ & 45.68 & 48.02 & 95.1 \\
& $8 \mathrm{x}$ & 20.88 & 24.01 & 87.0 \\
\hline \multirow{2}{*}{2} & - & 45.23 & - & - \\
& $2 \mathrm{x}$ & 23.37 & 22.61 & 103.3 \\
& $4 \mathrm{x}$ & 11.55 & 11.31 & 102.2 \\
& $8 \mathrm{x}$ & 6.71 & 5.65 & 118.6 \\
\hline
\end{tabular}

hsa-miR-93-5p miREIA

Sensitivity: $0.13 \mathrm{amol} / \mu \mathrm{L}$

miRNA immunoassay presented in his study is a 2-step nucleic acid capture immunoassay adapted to the Advia Centaur ${ }^{\circledR}$ Immunoassay System (Siemens Healthcare Diagnostics) $\left(\right.$ ref. $\left.^{24}\right)$.

In the assay, the purified miRNA from a blood sample is first hybridized to the biotinylated DNA probe, generating perfectly matched DNA/RNA heterohybrids:
Table 6. Intra-assay (Within-Run) ( $\mathrm{n}=8)$.

\begin{tabular}{cccc}
\hline Specimen & $\begin{array}{c}\text { Mean } \\
(\mathrm{amol} / \mu \mathrm{L})\end{array}$ & $\begin{array}{c}\mathrm{SD} \\
(\mathrm{amol} / \mu \mathrm{L})\end{array}$ & $\begin{array}{c}\mathrm{CV} \\
(\%)\end{array}$ \\
\hline 1 & 6.38 & 0.30 & 4.6 \\
2 & 1.41 & 0.10 & 6.7 \\
3 & 0.39 & 0.01 & 3.9 \\
\hline
\end{tabular}

hsa-miR-23a-3p miREIA

Sensitivity: $0.13 \mathrm{amol} / \mu \mathrm{L}$

Table 7. Inter-assay (Run-toRun) ( $n=5)$.

\begin{tabular}{cccc}
\hline Specimen & $\begin{array}{c}\text { Mean } \\
(\mathrm{amol} / \mu \mathrm{L})\end{array}$ & $\begin{array}{c}\text { SD } \\
(\mathrm{amol} / \mu \mathrm{L})\end{array}$ & $\begin{array}{c}\mathrm{CV} \\
(\%)\end{array}$ \\
\hline 1 & 319.09 & 14.81 & 4.6 \\
2 & 78.28 & 6.42 & 8.2 \\
3 & 40.08 & 2.47 & 6.17 \\
\hline
\end{tabular}

hsa-miR-23a-3p miREIA

Sensitivity: $0.13 \mathrm{amol} / \mu \mathrm{L}$

Table 8. Spiking recovery.

\begin{tabular}{cccc}
\hline Specimen & $\begin{array}{c}\text { Observed } \\
(\mathrm{amol} / \mu \mathrm{L})\end{array}$ & $\begin{array}{c}\text { Expected } \\
(\mathrm{amol} / \mu \mathrm{L})\end{array}$ & $\begin{array}{c}\text { Recovery } \\
\text { O/E }(\%)\end{array}$ \\
\hline \multirow{3}{*}{1} & 26.46 & - & - \\
& 53.91 & 56.10 & 96.1 \\
& 35.54 & 42.40 & 83.8 \\
2 & 30.54 & 33.64 & 90.8 \\
\hline \multirow{2}{*}{2} & 17.87 & - & - \\
& 48.07 & 47.51 & 101.2 \\
& 33.41 & 33.81 & 98.8 \\
\hline
\end{tabular}

hsa-miR-23a-3p miREIA

Sensitivity: $0.13 \mathrm{amol} / \mu \mathrm{L}$

Table 9. Linearity.

\begin{tabular}{ccccc}
\hline Specimen & Dilution & $\begin{array}{c}\text { Observed } \\
(\mathrm{amol} / \mu \mathrm{L})\end{array}$ & $\begin{array}{c}\text { Expected } \\
(\mathrm{amol} / \mu \mathrm{L})\end{array}$ & $\begin{array}{c}\text { Recovery } \\
\mathrm{O} / \mathrm{E}(\%)\end{array}$ \\
\hline \multirow{3}{*}{1} & - & 25.93 & - & - \\
& $2 \mathrm{x}$ & 13.52 & 12.97 & 104.3 \\
& $4 \mathrm{x}$ & 6.33 & 6.48 & 97.6 \\
& $8 \mathrm{x}$ & 3.98 & 3.24 & 122.8 \\
\hline \multirow{2}{*}{2} & - & 58.01 & - & - \\
& $2 \mathrm{x}$ & 28.46 & 29.01 & 98.1 \\
& $4 \mathrm{x}$ & 14.90 & 14.50 & 102.7 \\
& $8 \mathrm{x}$ & 8.41 & 7.25 & 116.0 \\
\hline
\end{tabular}

hsa-miR-23a-3p miREIA

Sensitivity: $0.13 \mathrm{amol} / \mu \mathrm{L}$

In a second step, these biotinylated DNA/RNA heterohybrids are then incubated with and bound to the streptavidin-labelled solid phase. In the next step, the acridinium ester-labelled antibody to DNA/RNA heterohybrids is added. This antibody can bind only to perfectly matched heterohybrids and does not bind to mismatched heterohybrids. The amount of antibody bound will therefore be 
proportional to the amount of perfectly matched heterohybrids present in the reaction, which is proportional to the amount of that specific miRNA species present in the blood sample.

Chemiluminescence is then triggered by addition of acid and base reagent.

Using this setup, authors were able to obtain a prototype assay that can measure miRNAs from biological samples without any preamplification step, with great analytical specificity and sensitivity ${ }^{24}$.

Although many blood-based miRNAs can be profiled with the proposed assay, the sensitivity has to be further improved to measure other samples with lower miRNA concentrations, such as serum. This assay is currently a research assay that aims to lay the basis for further development, with the challenging goal to promote the usage of miRNA as clinical IVD tests.

Keller and collective successfully set-up and published the first immunoassay-based method using chemiluminiscence for absolute quantification of miRNA (ref. ${ }^{24}$ ).

The invention relates to a method of detecting nucleic acid molecules by immunoassay detection was patented with patent number WO2013135581 A1.

We saw the potential of this method and bought the licence for miRNA quantification on the basis of an immunoassay using monoclonal antibody specific to RNA/ DNA hybrid.

Many microRNAs (miRNAs) are reported as disease markers for various human pathologies ${ }^{18-21}$, but only a small fraction is translated to routine clinical use. Interlaboratory variability and the consequent potential misinterpretation of results seem to be the biggest constraints of miRNA biomarker functionality. Absolute quantification ensured by exact calibration may solve this problem and help to translate miRNA biomarkers to diagnostic use. To address this problem, we have used a novel method for quantification of miRNA based on immunoassay, the miREIA - microRNA Enzyme Immunoassay kit. We believe that exact quantification and excellent reproducibility are the key values of the miREIA kits. Currently we are performing a number of projects involving parobands with cardiac conditions, patiens with malignancy, probands with metabolic syndrome and probands with neurodegeneration. In the above cases, clasiccal laboratory medicine fails.

\section{CONCLUSION}

In conclusion, in the pilot mini-study, the results measured with commercial miREIA kits exhibited significantly lower Run-to-Run variations (4-13\% and 5-17\% for hsa-miR-93-5p and hsa-miR-23a-3p, respectively) than results with the RT-qPCR commercial kits (49-81\% and 17-25\% for hsa-miR-93-5p and hsa-miR-23a-3p, respectively). Both types of analyses do not differ after simple mathematical normalisation of data. The results need to be confirmed in clinical studies which we are performing or will be performing. Molecular applications such as RT-
qPCR use amplification and reverse transcription steps, which are characterized by high inter-assay variability compared to immunoassays. In addition, they work with sample volumes in the low microliter $(\mu \mathrm{L})$ range, further increasing susceptibility to unwanted sample variability. The advantage of the miREIA assay is that the test can be performed on any device that processes the ELISA plates and is therefore available in almost every laboratory.

Author contributions: DS, RS: research, data collection, measurement; ZS, KA, MS: research; MH: development, design of new ELISA test (miREIA), miRNA measurement.

Conflict of interest statement: David Stejskal, Radka Sigutova, Zdeněk Svagera, Katerina Andelova, Marek Svestak: None declared. Martina Hlozankova is director of R\&D Biovendor a.s.

\section{REFERENCES}

1. Chen PY, Meister G. microRNA-guided posttranscriptional gene regulation. Biol Chem. 2005; 386(12):1205-18. Review

2. Gottmann $P$, Ouni $M$, Sausenthaler $S$, Roos J, Stirm L, Jähnert M, Kamitz A, Hallahan N, Jonas W, Fritsche A, Häring HU, Staiger $H$, Blüher M, Fischer-Posovszky P, Vogel H, Schürmann A. A computational biology approach of a genome-wide screen connected miRNAs to obesity and type 2 diabetes. Mol Metab 2018;11:145-59. doi: 10.1016/j.molmet.2018.03.005

3. Yang TT, Liu CG, Gao SC, Zhang Y, Wang PC. The Serum Exosome Derived MicroRNA-135a, -193b, and-384 Were Potential Alzheimer's Disease Biomarkers. Biomed Environ Sci 2018;31(2):87-96. doi: 10.3967/bes2018.011

4. McKeever PM, Schneider R, Taghdiri F, Weichert A, Multani N, Brown RA, Boxer AL, Karydas A, Miller B, Robertson J, Tartaglia MC.MicroRNA Expression Levels Are Altered in the Cerebrospinal Fluid of Patients with Young-Onset Alzheimer's Disease. Mol Neurobiol 2018; 55(12):8826-41. doi: 10.1007/s12035-018-1032-x

5. Kian R, Moradi S, Ghorbian S. Role of components of microRNA machinery in carcinogenesis. Exp Oncol 2018;40:2-9.

6. http://www.mirbase.org/

7. Fan J, Li H, Nie X, Yin Z, Zhao Y, Zhang X, Yuan S, Li Y, Chen C, Wang DW. MiR-665 aggravates heart failure via suppressing CD34mediated coronary microvessel angiogenesis. Aging (Albany NY) 2018;10(9):2459-79. doi: 10.18632/aging.101562. [Epub ahead of print]

8. Zhong X, Yang S, Yang P, Du H, Hou X, Chen J, Zhou R.Designing DNAzyme-Powered Nanomachines Simultaneously Responsive to Multiple MicroRNAs. Chemistry 2018;Sep 22. doi: 10.1002/ chem.201804127. [Epub ahead of print]

9. Godfrey TC, Wildman BJ, Beloti MM, Kemper AG, Ferraz EP, Roy B, Rehan M, Afreen LH, Kim E, Lengner CJ, Hassan Q. The microRNA-23a cluster regulates the developmental HoxA cluster function during osteoblast differentiation. J Biol Chem 2018;293(45):17646-60. doi: 10.1074/jbc.RA118.003052

10. Drobna M, Szarzyńska-Zawadzka B, Daca-Roszak P, Kosmalska M, Jaksik R, Witt M, Dawidowska M. Identification of Endogenous Control miRNAs for RT-qPCR in T-Cell Acute Lymphoblastic Leukemia. Int J Mol Sci 2018;19(10):pii:E2858. doi: 10.3390/ijms19102858

11. Zhang P, Du J, Wang L, Niu L, Zhao Y, Tang G, Jiang Y, Shuai S, Bai L, Li X, Wang J, Zhang S, Zhu L. MicroRNA-143a-3p modulates preadipocyte proliferation and differentiation by targeting MAPK7. Biomed Pharmacother 2018;108:531-9. doi: 10.1016/j.biopha.2018.09.080

12. Zhu H, Leung SW. Identification of Potential MicroRNA Biomarkers by Meta-analysis. Methods Mol Biol 2018;1762:473-84. doi: 10.1007/978-1-4939-7756-7_24

13. Amin M, Islam F, Gopalan V, Lam AK. Detection and Quantification of MicroRNAs in Esophageal Adenocarcinoma. Methods Mol Biol 2018;1756:257-68. doi: 10.1007/978-1-4939-7734-5_22 
14. Etheridge A, Wang K, Baxter D, Galas D. Preparation of Small RNA NGS Libraries from Biofluids. Methods Mol Biol 2018;1740:163-75. doi: 10.1007/978-1-4939-7652-2_13

15. Ren FH, Yang H, He RQ, Lu JN, Lin XG, Liang HW, Dang YW, Feng ZB, Chen G, Luo DZ. Analysis of microarrays of miR-34a and its identification of prospective target gene signature in hepatocellular carcinoma. BMC Cancer 2018;18:12. doi: 10.1186/s12885-017-3941-x

16. Chen X, Zhang Q, Ma W, Lan T, Hong Z, Yuan Y. The Abnorma Expression of MicroRNA-542-3p in Hepatocellular Carcinoma and Its Clinical Significance. Dis Markers 2018;2018:3973250. doi: $10.1155 / 2018 / 3973250$

17. Lian J, Lin SH, Ye Y, Chang DW, Huang M, Dinney CP, Wu X. Serum microRNAs as predictors of risk for non-muscle invasive bladder cancer. Oncotarget 2018;9:14895-908. doi: 10.18632/oncotarget.24473

18. Huang J, Wu J, Li Y, Li X, Yang T, Yang Q, Jiang Y. Deregulation of serum microRNA expression is associated with cigarette smoking and lung cancer. Biomed Res Int 2014;2014:364316. doi: $10.1155 / 2014 / 36431$
19. Konta T, Ichikawa K, Suzuki K, Kudo K, Satoh H, Kamei K, Nishidate $\mathrm{E}$, Kubota A microarray analysis of urinary microRNAs in renal diseases. Clin Exp Nephrol 2014;18(5):711-7. doi: 10.1007/s10157-0130906-5

20. Yin JQ, Zhao RC, Morris KV. Profiling microRNA expression with microarrays. Trends Biotechnol 2008;26:70-6.

21. Dard-Dascot C, Naquin D, d'Aubenton-Carafa Y, Alix K, Thermes C, van Dijk E.Systematic comparison of small RNA library preparation protocols for next-generation sequencing. BMC Genomics 2018;19(1):118. doi: 10.1186/s12864-018-4491-6

22. Creighton CJ, Reid JG, Gunaratne PH. Expression profiling of microRNAs by deep sequencing. Brief Bioinform 2009;10:490-7.

23. Kappel A, Keller A. miRNA assays in the clinical laboratory: workflow, detection technologies and automation aspects. Clin Chem Lab Med 2017;55(5):636-47. doi: 10.1515/cclm-2016-0467

24. Kappel A, Backes C, Huang Y, Zafari S, Leidinger P, Meder B, Schwarz $\mathrm{H}$, Gumbrecht W, Meese E, Staehler CF, Keller A. MicroRNA in vitro diagnostics using immunoassay analyzers. Clin Chem 2015;61(4):6007. doi: 10.1373/clinchem.2014.232165 